\title{
Correlation between Field Formation, Proton Translocation, and the Light Reactions in Photosynthesis *
}

\author{
W. Schliephake, W. Junge, and H. T. Witt \\ Max-Volmer-Institut, I. Institut für Physikalische Chemie, Technische Universität Berlin \\ (Z. Naturforschg. 23 b, 1571-1578 [1968]; eingegangen am 7. September 1968)
}

\begin{abstract}
Electrical field changes across the function membrane of photosynthesis have been measured via special absorption changes. These occur by the action of the field on pigments which are located within the membrane. - Proton translocation has been measured by absorption changes of added $\mathrm{pH}$ indicators. Repetitive flash technique has been used for the sensitive detection of these absorption changes.

1. Each of the two light reactions of photosynthesis sets on one half of the electrical field.

2. The action spectra indicate that the two light reactions which set on the field are identical with those which promote the electron transfer.

3. The voltage set on in the elementary act both light reactions is $V_{0}=50 \mathrm{mV}$.

4. Each of the two light reactions translocates one proton across the membrane.

5. The proton uptake is faster than $8 \cdot 10^{-3}$ sec.

6. Two protons are translocated per one electron transferred to a terminal acceptor.

7. A reaction scheme compatible with the measured correlation between the light reactions, electron transfer, field formation, and proton translocation is depicted in Fig. 7.
\end{abstract}

1. In the primary processes of photosynthesis electrons are transferred from water to $\mathrm{NADP}^{\oplus}$ through at least ten electron carriers by the energy of two light reactions. The results obtained in this respect especially by the pulse techniques are discussed in l. c. ${ }^{1}$.

2. Simultaneously with the electron transfer ATP is synthesized from ADP and inorganic phosphate 2 .

3. Furthermore with the electron transfer ion translocations have been observed. Protons are taken up in exchange with other cations ${ }^{3,4}$.

4. Moreover, evidence has been provided that with the electron transfer an onset of an electrical field across a membrane takes place ${ }^{5}$.

5. The function unit of phosphorylation, ion translocations, and field changes is the membrane of one thylakoid ${ }^{5,6}$.

* Presented on the Photosynthesis Meeting in Freudenstadt on June 7, 1968.

1 H. T. WrtT, in: Fast Reactions and Primary Processes in Chemical Kinetics (Nobel Symposium V). Ed. S. Claesson, 1967, p. 261, Almqvist \& Wiksell, Stockholm; Interscience Publ., New York, London, Sydney.

2 D. I. Arnon, M. B. Allen, and F. R. Whatley, Nature [London] 174394 [1954].

3 A. T. JAGendorf and G. Hind, Photosynth. Mech. of Green Plants, NAS-Nat. Res. Councils Publ. 1145, 699 [1963].

4 L. A. Dilley and L. P. Vernon, Arch. Biochem. Biophysics 111, 365 [1965].

5 W. Junge and H. T. Witt, Z. Naturforschg. 23 b, 244 [1968].

6 W. Junge, E. Reinwald, B. Rumberg, U. Siggel, and H. T. Witr, Naturwissenschaften 55, 36 [1968].

7 P. Mitchell, Nature [London] 191, 144 [1961] ; Biol. Rev. Cambridge philos. Soc. 41, 445 [1966].
Mitchell postulated that the free energy necessary for the synthesis of ATP may be gained with the translocation of protons "down hill" a proton gradient and a voltage gradient across a membrane $^{7}$. This idea is supported by several facts.

a) If an antificial $\mathrm{pH}$-gradient is set up on chloroplasts, a formation of ATP can be observed in the dark ${ }^{8}$.

b) In vivo, it has been demonstrated that the synthesis of ATP in the light is coupled with a field driven extra proton efflux out of the thylakoid ${ }^{\mathbf{9}, 5}$.

c) Furthermore, it has been shown that the synthesis of ATP is coupled with a diffusion driven extra efflux of protons out of the thylakoid ${ }^{\mathbf{1 0}}$.

d) A number of other results giving experimental evidence in photosynthesis for the hypothesis of Mitchell and results which extend the concept, have been presented in 1. c. $^{5,6}$ and in l.c. ${ }^{9-15}$. In the

8 A. T. Jagendorf and E. Uribe, Proc. nat. Acad. Sci. USA 55,170 [1966].

9 B. Rumberg and U. Siggel, Z. Naturforschg. 23 b, 239 [1968].

10 B. Rumberg, E. Reinwald, H. Schröder, and U. Siggel, Naturwissenschaften 55, 77 [1968].

11 E. Reinwald, U. Siggel, and B. Rumberg, Naturwissenschaften 55, 221 [1968].

12 E. Reinwald, U. Siggel, and B. Rumbrug, Z. Naturforschg. 23 b, 1616 [1968].

13 B. Rumberg, U. Siggel, and E. Reinwald, Naturwissenschaften, in press.

14 Ch. Wolff, H.-E. Buchwald, H. Rüppel, K. Witt, and H. T. Witr, Z. Naturforschg., in press.

15 H. T. Witt, B. Rumberg, and W. Junge, 19. Mosbach Colloquium 1968. Springer-Verlag, S. 262. 
further development of the concept the following questions are of interest.

a) Does there exist a definite ratio of electron transfer and $H^{\oplus}$-translocation which demonstrates the coupling of both?

b) What is the correlation of the $\mathrm{H}^{\oplus}$-translocation with respect to the two light reactions?

c) What is the correlation of the electrical field formation with respect to the two light reactions?

d) What is the mechanism of the coupling between these four events?

These questions are the subject of the following experiments.

Only the first question concerning the coupling between electron transfer and proton translocation has been studied by several authors. They determined the stoichiometric ratio between the number of protons taken up by chloroplasts $\left(\Delta \mathrm{H}^{\oplus}\right)$ and the number of electrons transferred to a terminal electron acceptor $\left(\Delta \mathrm{e}^{\ominus}\right)$ in steady illumination ${ }^{16-18,13}$. The results of Izawa et al. in l.c. ${ }^{16}$ showed an uptake of 2 protons per 1 electron transfer. This was confirmed in l. c. ${ }^{13}$. However in l. c. ${ }^{18}$ it is reported on $2-6$ protons per 1 electron transfer. This result have been quoted by KarLish and Avron ${ }^{18}$ against a fixed coupling between electron transfer and proton translocation.

As will be shown in l.c. ${ }^{13}$ the discrepancy in the ratio of $\Delta \mathrm{H}^{\oplus} / \Delta \mathrm{e}^{\ominus}$ cited above is caused through the change of the rate of the electron transfer in the beginning of the illumination before the steady state is reached. This has not been regarded in l. c. ${ }^{18}$.

To avoid these difficulties, in the following the $\Delta \mathrm{H}^{\oplus} / \Delta \mathrm{e}^{\ominus}$ ratio is measured in the elementary act. In the elementary act which can be realized by excitation of the photochemical active pigments with flashes shorter than $\ll 6 \cdot 10^{-4}$ s, see l. c. ${ }^{15}$, each light reaction acts only on one electron. Therefore, only one electron is transported across each of the possible coupling sites between electron transfer and proton translocation. Measurements of rates can be completely avoided and therefore also the complications mentioned above for steady illumination.

16 S. Izawa and G. Hind, Biochim. biophysica Acta [Amsterdam] 143, 377 [1967].

17 W. S. Lynn and L. Brown, J. biol. Chemistry 242, 412 412 [1967].

18 S. J. D. Karlish and M. Avron, Nature [London] 216, 1107 [1967] ; BBA 153, 879 [1968].

19 D. Winget, S. Izawa, and N. E. Good, B. B. Res. Commun. 21, 438 [1965].

\section{Materials and Methods}

The experiments were carried out on suspensions of spinach chloroplasts prepared by a method proposed by $\mathrm{W}_{\text {INGET }}$ et al. ${ }^{19}$. The repetitive flash photometry was used as measuring technique. Details of the apparatus and of the methods have been described elsewhere ${ }^{20,21}$.

The number of protons taken up by the thylakoids on flash-light excitation was calculated from the $\mathrm{pH}$ change in the chloroplasts suspension. The $\mathrm{pH}$-change was measured photometri cally by $\mathrm{pH}$ indicators as brom-thymol-blue BTB ${ }^{22}$. The improvement of the signal to noise ratio by repetitive measuring techniques resulted in a resolution of $\mathrm{pH}$-jumps of less than $10^{-4}$ units (at $\mathrm{pH} 6,8)$ with a time resolution of $2 \cdot 10^{-4} \mathrm{sec}$. The time resolution of the whole apparatus corresponds to $7 \cdot 10^{-5}$ sec.

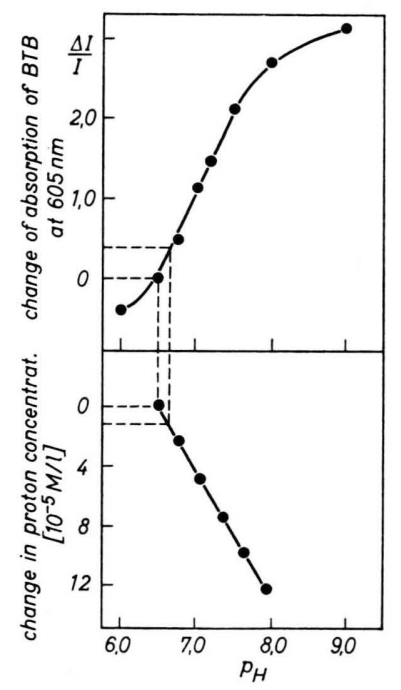

Fig. 1. Top: Change in the absorption of the $\mathrm{pH}$ indicator bromthymol blue (BTB) at $605 \mathrm{~nm}$ as a function of the $\mathrm{pH}$. Bottom: Change of the proton concentration in dependence of the $\mathrm{pH}$ in a chloroplast suspension of spinach. Chlorophyll concentration: $10^{-5} \mathrm{M} / l$, activity of $\mathrm{O}_{2}$-production $7,2 /(24)$ $\mathrm{mm}\left(\mathrm{O}_{2}\right) / \mathrm{M}(\mathrm{Chl}) \cdot \mathrm{s}$, activity of ATP-production $20,2 \mathrm{~mm}$ $(\mathrm{ATP}) / \mathrm{M}(\mathrm{Chl}) \cdot \mathrm{s}$. Electron acceptor: Benzylviologen $5 \cdot 10^{-5}$ $\mathrm{M} / l$. Furter additions: $\mathrm{KCl} 3 \cdot 10^{-2} \mathrm{M} / \mathrm{l}$. Saccharose $6 \cdot 10^{-1}$ $\mathrm{M} / l$. BTB $3 \cdot 10^{-5} \mathrm{M} / l$.

Fig. 1 (bottom) shows the change in the proton concentration in dependence of the $\mathrm{pH}$ in a chloroplast suspension. The $\mathrm{pH}$ has been measured by a glass electrode, the proton concentration has been changed by addition of small amounts of $\mathrm{NaOH}$. In fig. 1 (top) the dependence of the absorption change of BTB at

20 H. T. Wirt, in: Fast Reactions and Primary Processes in Chemical Kinetics (Nobel Symposium V). Ed. S. Clabsson, 1967, p. 81, Almqvist \& Wiksell, Stockholm; Interscience Publ., New York, London, Sydney.

21 H. Rüppel and H. T. Witt, Methods in Enzymology, ed. S. P. Colowick and N. O. Kaplan, Academic Press, New York 1968.

22 B. Chance and L. Mela, NAS-US 55, 1243 [1966]. 
$605 \mathrm{~nm}$ on $\mathrm{pH}$ is depicted. To check that the BTB absorption change is a true indication of the $\mathrm{pH}$-changes in chloroplast suspensions it was confirmed that:

a) The electron transport and the phosphorylation activity of chloroplasts were practically not altered (less than 10 per cent) on addition of BTB to a final concentration of $3 \cdot 10^{-5} \mathrm{M} / l$.

b) The absorption change of BTB at $605 \mathrm{~nm}$ was clearly separable from other slow optical effects due to light scattering, intrinsic absorption changes, etc. at this wavelength (see fig. 2).

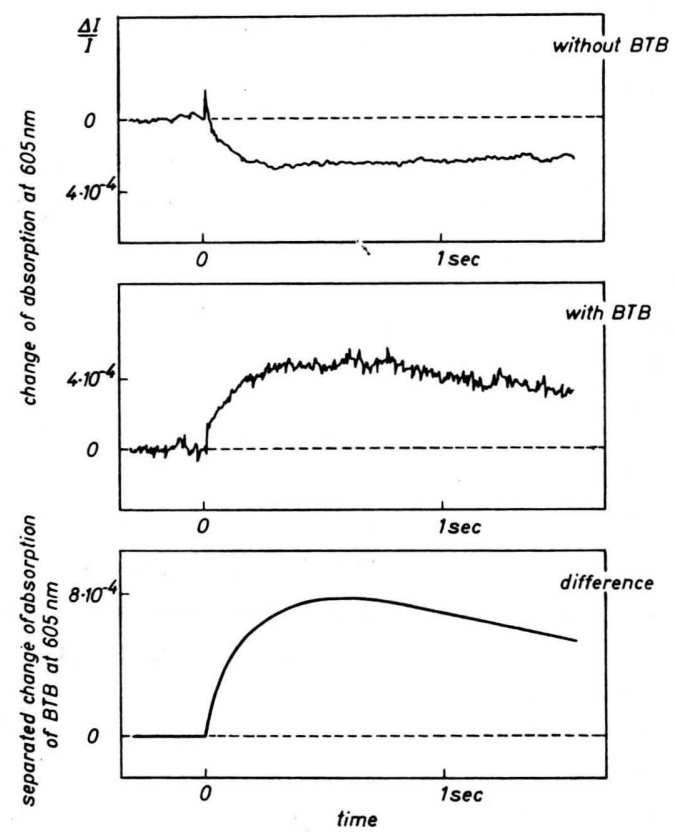

Fig. 2. Time course of the absorption change at $605 \mathrm{~nm}$ in spinach chloroplasts. Top: without BTB, center: with BTB, bottom: separated absorption change of BTB. Chorophyll concentration: $10^{-5} \mathrm{M} / l$, activity of $\mathrm{O}_{2}$-production $5,1 /(20,1)$ $\mathrm{mM}\left(\mathrm{O}_{2}\right) / \mathrm{M}(\mathrm{Chl}) \cdot \mathrm{s}$, activity of ATP-production $20 \mathrm{mM}$ (ATP) $/ \mathrm{M}(\mathrm{Chl}) \cdot \mathrm{s}$. pH 6,8. Electron acceptor: Benzylviologen $5 \cdot 10^{-5} \mathrm{M} / l$. Further additions: $\mathrm{KCl} 3 \cdot 10^{-2} \mathrm{M} / l$. Saccharose $6 \cdot 10^{-1} \mathrm{M} / l$. BTB $3 \cdot 10^{-5} \mathrm{M} / l$. Reaction volume $10 \mathrm{ml}$. Path length through the cuvette $20 \mathrm{~mm}$. Excitation: wavelength $400-500 \mathrm{~nm}$ (coloured glasses BG $28-4 \mathrm{~mm}$; heat reflection filter T 8), duration $15 \mu \mathrm{s}$, frequency $0,4 \mathrm{cps}$, saturating intensity. Measuring beam: wavelength $605 \mathrm{~nm}$, grating monochromator, optical bandwidth $\Delta \lambda=5 \mathrm{~nm}$, intensity $<400 \mathrm{erg} / \mathrm{cm}^{2} \mathrm{~s}$. $T=22{ }^{\circ} \mathrm{C}$. Electrical bandwidth $\Delta v=1,4 \mathrm{kcps}$. Repetitive flash photometry, about 500 flashes were fired.

c) The pH-changes in chloroplast suspensions indicated by the absorption change of BTB in long flashes and steady illumination respectivily have been controlled by $\mathrm{pH}$-measurements with a glass

* The authors are indepted to Dipl.-Ing. E. REInwald for carrying out these measurements.

23 B. Koк, S. Malkin, and O. Owens, Brookhaven Sympos. in Biology, No. 19 [1966]. electrode *. Sufficient agreement of the steady state values of $\mathrm{pH}$-changes has been found.

The number of electron transfers has been measured by the oxidation of chlorophyll-a via the absorption change of Chl-a at $705 \mathrm{~nm}$. The calibration of the change in the extinction coefficient by the oxidation of chlorophyll-aI at $705 \mathrm{~nm}$ has been carried out by a comparison with the absorption changes of the electron acceptor 2,6-dichlorophenolindophenol (DPIP) at 605 nm. It has been shown that the rapid phase of the reduction of DPIP takes place at the end of the whole electron transport chain ${ }^{23}$.

Using the change of the extinction coefficient of DPIP at its reduction as determined by Punnet ${ }^{24}$, the change of the extinction coefficient of chlorophyll-ai at its oxidation has been determined as $\Delta \varepsilon_{705}=4,2 \cdot 10^{4} l$ $\mathrm{M} \cdot \mathrm{cm}$.

This value is about 20 per cent bigger than the value published by Rumberg and Schmidt-Mende 25 which has been determined with $\mathrm{K}_{3} \mathrm{Fe}(\mathrm{CN})_{6}$ as acceptor that is known to accept electrons at higher concentration also between the two light reactions ${ }^{\mathbf{2 6}}$.

\section{Results}

\section{The Stoichiometry of Proton Translocation and Electron Transfer in the Elementary Act}

The $\Delta \mathrm{H}^{\oplus} / \Delta \mathrm{e}^{\ominus}=\Delta \mathrm{H}^{\oplus} / \Delta \mathrm{Chl}-\mathrm{a}_{\mathrm{I}}$ ratio has been measured for electron acceptors that are known to accept one proton per electron: benzylviologen, thymol-indophenol (TIP), safranine T, indigo carmine. The number of protons taken up by the chloroplasts in the elementary act has been calculated from the absorption change of BTP (fig. 3, top, left side), the number of electrons transported from the absorption changes of chlorophyll-a I (fig. 3 , bottom, left side).

The results are depicted in table 1 . For all these acceptors about two protons were taken up per one electron transported across chlorophyll- $\mathrm{a}_{\mathrm{I}}$. This result is in agreement with those values of IzAwA and Hind ${ }^{16}$, and Rumberg et al. ${ }^{12}$ which have been extrapolated fort he beginning of steady illumination.

\section{Correlation between the Proton Translocation and the two Light Reactions}

The value of two protons translocated per one electron transported across chlorophyll $\mathrm{a}_{\text {I }}$ may indicate the existence of two univalent coupling sites,

24 W. Punnet, Plant Physiol. 34, 283 [1959].

25 B. Rumberg and P. Schmidt-Mende, Z. Naturforschg. 23 b, 225 [1968].

26 P. Schmidt-Mende and H. T. Witt, Z. Naturforschg. 23 b, 228 [1968]. 


\begin{tabular}{lc}
\hline Acceptor A & $\Delta \mathrm{H}^{\oplus} / \Delta \mathrm{e}^{\ominus}$ \\
\hline Benzylviologen & 1,93 \\
& 2,23 \\
& 1,65 \\
& 2,05 \\
TIP & 2,08 \\
& 2,32 \\
& 2,06 \\
& 2,09 \\
Safranine T & 2,04 \\
& 1,65 \\
Indigocarmine & 2,01 \\
& 2,19 \\
& 1,85
\end{tabular}

Table 1. Ration between the number of protons taken up by the chloroplasts $\left(\Delta \mathrm{H}^{\oplus}\right)$ and the number of electrons transferred to a terminal eleetron acceptor $\left(\Delta \mathrm{e}^{\ominus}\right)$ in the elementary act. Experimental conditions as in fig. 3, left. (The measurements were carried out on chloroplast preparations of various activities of $0_{2}$ - and ATP-formation. Concentration of the electron acceptors $5 \cdot 10^{-5} \mathrm{M} / l$ ).
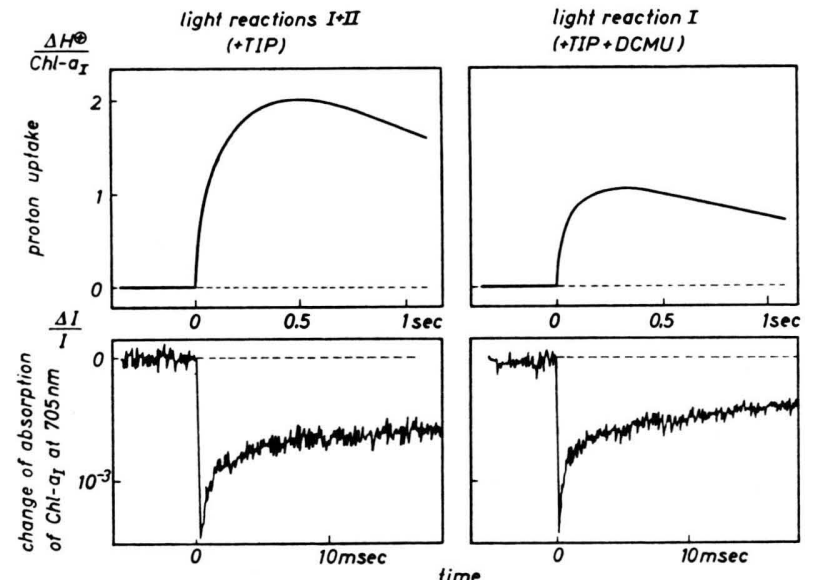

Fig. 3. Top: Proton uptake $\Delta \mathrm{H}^{\odot}$ (indicated by the separated absorption change of BTB at $605 \mathrm{~nm}$ ) per photoactive chlorophyll-aI. Bottom: Time course of the absorption change of chlorophyll-aI at $705 \mathrm{~nm}$. Left: Light reactions I and II (TIP). Right : Light reaction I only (TIP + DCMU). Chlorophyll concentration $10^{-5} \mathrm{M} / l$, activity of $\mathrm{O}_{2}$-production $4,2 /(28) \mathrm{mM}$ $\left(\mathrm{O}_{2}\right) / \mathrm{M}(\mathrm{Chl}) \cdot \mathrm{s}$, activity of ATP-production $20 \mathrm{mM}$ (ATP)/ $\mathrm{M}(\mathrm{Chl}) \cdot \mathrm{s}$. $\mathrm{pH}$ 7,4. Electron acceptor: Thymolindophenol (TIP) $5 \cdot 10^{-5} \mathrm{~m} / l$. Further additions: $\mathrm{KCl} 3 \cdot 10^{-2} \mathrm{M} / l$. Saccharose $6 \cdot 10^{-1} \mathrm{M} / l$. BTB $3 \cdot 10^{-5} \mathrm{M} / l$ DCMU $2 \cdot 10^{-6} \mathrm{M} / l$ (right). Reaction volume $10 \mathrm{ml}$. Path length through the cuvette $20 \mathrm{~mm}$. Excitation: wavelength $400-500 \mathrm{~nm}$ (coloured glasses BG $28-4 \mathrm{~mm}$; heat reflection filter T 8), duration $15 \mu \mathrm{s}$, frequency $0,4 \mathrm{cps}$, saturating intensity. Measuring beam: wavelength $605-705 \mathrm{~nm}$, grating monochromator, optical bandwidth $\Delta \lambda=5 \mathrm{~nm}$, intensity $<400 \mathrm{erg} / \mathrm{cm}^{2} \mathrm{~s} . T=$ $22{ }^{\circ} \mathrm{C}$. Electrical bandwidth $\Delta v=1,4(12) \mathrm{kcps}$. Repetitive flash photometry. About 500 flashes were fired.

each of which is attributable to one of the two light reactions. Alternatively it may indicate the existence of two coupling sites both associated with one and the same of the light reaction.
A discrimination between the two alternative possibilities can be achieved by the measurement of the $\Delta \mathrm{H}^{\oplus} / \Delta \mathrm{e}^{\ominus}$ ratio when light reaction I has been chemically separated by addition of 3-(3,4-dichlorophenyl-)-1,1-dimethylurea (DCMU) with TIP. DCMU desactivates light reaction II ${ }^{27}$. Under these conditions light reaction $I$ is full active as can be seen from the absorption change of chlorophyll-a $\mathrm{a}_{\mathrm{I}}$ in fig. 3 (bottom, right side). Fig. 3 (top, right side) demonstrates that the proton uptake is decreased by a factor of 2 on addition of DCMU. From the $\Delta \mathrm{H}^{\oplus} /$ $\Delta \mathrm{e}^{\ominus}$ ratio of 1 under these conditions it can be seen that the ligh reaction I mediated by TIP translocates one proton only. Very probably this means that when light reactions I + II are in action the second proton is translocated by light reaction II. Therefore, in the elementary act each of the two light reactions translocates one proton across the thylakoid membrane.

\section{Correlation between the Field Formation and the two Light Reactions.}

Evidence has been provided that the characteristic absorption changes at 478,515 , and $648 \mathrm{~nm}$ (chlorophyll-b) on spinach chloroplasts are a molecular indicator for an onset of an electrical field across the thylakoid membrane ${ }^{5}$.

This field is set on in illumination in less than $2 \cdot 10^{-8} \sec ^{1,14}$ and decays by ion fluxes in the range of $10-100 \mathrm{msec}$, depending on temperature, $\mathrm{pH}$ and the state of the membrane. The translocation of two protonic charges across the thylakoid membrane and the onset of an electrical field may be coupled with each other. In this case it has to be expected that both light reactions participate in equal parts in charging the membrane capacity, as they do so in proton translocation. Indeed, a cor. responding result to that of fig. 3 has been obtained comparing the absorption change of chlorophy-b at $515 \mathrm{~nm}$ in fig. 4 in three cases a) when both light reactions were active, b) when only light reaction I was active, and c) when only light reaction II was active.

Light reaction I has been separated from the overall reaction by addition of TIP and DCMU. Light reaction II has been separated from the overall reaction by addition of ferricyanide (Fecy) and DPIP ${ }^{30}$.

27 G. Döring, H.-H. Stiehl, and H. T. Witt, Z. Naturforschg. 22 b, 639 [1967]. 

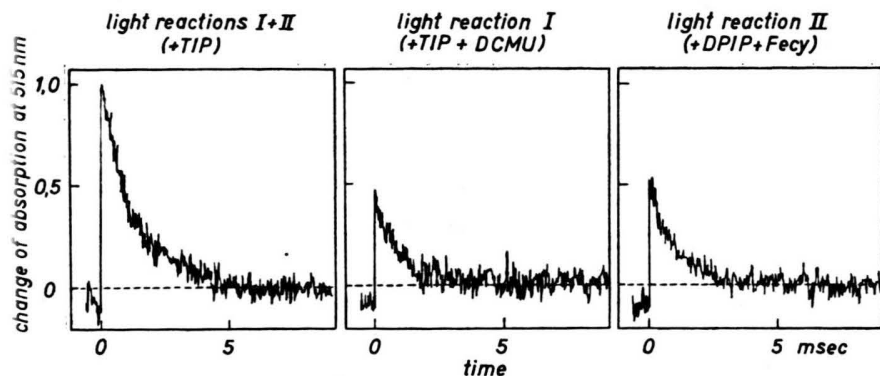

Fig. 4. Time course of the absorption change of chlorophyll-b at $515 \mathrm{~nm}$. Left: Light reaction I and II (TIP). Center: Light reaction I only (TIP + DCMU). Right: Light reaction II only (DPIP + Fecy). Chlorophyll-concentration $10^{-4} \mathrm{M} / l$, activity of $\mathrm{O}_{2}$-production $5,5(36) \mathrm{mM}\left(\mathrm{O}_{2}\right) / \mathrm{M}(\mathrm{Chl}) \cdot \mathrm{s}$, activity of ATP. production $43,3 \mathrm{mM}(\mathrm{ATP}) / \mathrm{M}(\mathrm{Chl}) \cdot \mathrm{s}$. Tricine $\mathrm{NaOH}$-buffer: pH 7,$4 ; 10^{-3} \mathrm{M} / l$. Electron acceptor: TIP, resp. DPIP each $5 \cdot 10^{-5} \mathrm{M} / l$. Further additions: $\mathrm{KCl} 2 \cdot 10^{-2} \mathrm{M} / l$. Gramicidin D $10^{-9} \mathrm{M} / l$. Center: DCMU $2 \cdot 10^{-6} \mathrm{M} / l$. Right: Fecy $10^{-3}$ $\mathrm{M} / l$. Reaction volume $1 \mathrm{ml}$. Path length through the cuvette $1,4 \mathrm{~mm}$. Excitation: wavelength $630-680 \mathrm{~nm}$, (coloured glasses RG 1-4 mm; heat reflection filter T 8), duration $15 \mu$, frequency $2,5 \mathrm{cps}$, saturating intensity. Measuring beam: wavelength $515 \mathrm{~nm}$, grating monochromator, optical bandwidth $\Delta \lambda=5 \mathrm{~nm}$, intensity $<400 \mathrm{erg} / \mathrm{cm}^{2} \mathrm{~s}$. $T=22^{\circ} \mathrm{C}$. Electrical bandwidth $\Delta v=12 \mathrm{kcps}$. Repetitive flash photometry. About 500 flashes were fired.

From fig. 4 it can be seen that the absorption changes at $515 \mathrm{~nm}$ with light reaction I only, or light reaction II only, are by a factor 2 smaller than those with light reaction I + II. This has been proved for each of the three characteristic changes of Chl-b at 478,515 , and $648 \mathrm{~nm}$. This demonstrates clearly that in the elementary act each of the two light reactions set on one half of the field.

That the absorption changes at $515 \mathrm{~nm}$ can be excited by each of both light reactions is a wellknown phenomenon. It has been demonstrated in different ways by $\mathrm{W}_{\text {ItT }}$ et al. ${ }^{28}$, Rumberg ${ }^{29}$, and Witr et al. ${ }^{30}$.

Witr et al. ${ }^{28}$ compared the absorption changes of chlorophyll-b together with those of cytochrome-f oxidation by excitation with $h v_{\mathrm{I}}$-light $(\lambda=720 \mathrm{~nm})$ and $h v_{\mathrm{I}^{-}}+h v_{\mathrm{II}}$-light $(\lambda<700 \mathrm{~nm})$ respectively. In

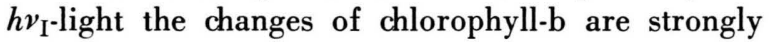
decreased compared with the changes in $h v_{\mathrm{I}}+h v_{\mathrm{II}}$. The absorption changes of cytochrome-f are, however, the same in both lights. From this effect (and the characteristic kinetics) it was derived that photosynthesis is run by two light reactions coupled in series see 1. c. $^{28}$. Rumberg ${ }^{29}$ demonstrated that the

28 H. T. Witt, A. Müller, and B. Rumberg, Nature [London] 191, 194 [1961].

29 B. Rumberg, Nature [London] 204, 860 [1964]. contribution of each light reaction to the changes of chlorophyll-b is one half, using also $h v_{\mathrm{I}^{-}}$and $h v_{\mathrm{I}^{-}}+$ $h v_{\mathrm{II}}$-light respectively. WITT et al. ${ }^{30}$ came to the same conclusion by a chemical separation of light reaction II from the overall reaction with addition of ferricyanide + DPIP.

An new feature in the result of fig. 4 is that the absorption changes at $515 \mathrm{~nm}$ show the same decay rate, no matter which of the two light reactions is active or both together. In fig. 4 the half time of the decay has been accelerated by addition of gramicidin $D$ to the ad lib. value of 0,7 $\mathrm{msec}^{5}$. In table 2 the half times or the decay are compared at different concentrations of gramicidin.

\begin{tabular}{cccc}
\hline $\begin{array}{c}\text { Gramici- } \\
\text { din D } \\
M / l\end{array}$ & $\begin{array}{c}\tau_{1 / 2}(515 \mathrm{~nm}) \\
\text { I+ II } \\
{[\mathrm{msec}]}\end{array}$ & $\begin{array}{c}\tau_{1 / 2}(515 \mathrm{~nm}) \\
\text { I } \\
{[\mathrm{msec}]}\end{array}$ & $\begin{array}{c}\tau_{1 / 2}(515 \mathrm{~nm}) \\
\text { II } \\
\text { [msec] }\end{array}$ \\
\hline 0 & 12,2 & 11,5 & 12,5 \\
$10^{-10}$ & 5,3 & 4,8 & 4,9 \\
$3 \cdot 10^{-10}$ & 1,9 & 1,7 & 1,7 \\
$10^{-9}$ & 0,6 & 0,8 & 0,6 \\
\hline
\end{tabular}

Table 2. Rate of the decay of the absorption change of chlorophyll-b at $515 \mathrm{~nm}$ in dependence of the concentration of Gramicidin D if the light reactions I+II (TIP) are active, if light reaction I (TIP + DCMU) is active solely, and light reaction II (DPIP + Fecy) is active solely respectively. Experimental conditions as in fig. 4 .

Thus, it can be concluded from these experiments that the two absorption changes at $515 \mathrm{~nm}$, one excitable by light reaction $I$ and the other by light reaction II, reflect the same physical event (an electrical field across the thylakoid membrane ${ }^{5}$ ).

\section{Action Spectra of the Field Formation}

The identity of the light reactions which set on the electrical field with those that promote the electron transport could be checked by measurements of the action spectra. Fig. 5 shows the action spectra for the field changes (absorption change at $515 \mathrm{~nm}$ ) if light reaction I was separated and when, on the other hand, light reaction II was separated. Light reaction $I$ has been separated from the overall reaction as in fig. 4 by TIP and DCMU. Light reaction II has been separated from the overall reaction as in fig. 4 by addition of ferricyanide and DPIP. The action spectra for the field changes (absorption

30 H. T. Witt, B. Rumberg, P. Schmidt-Mende, U. Siggel, B. Skerra, J. Vater, and J. Weikard, Angew. Chem. 77, 821 [1965]. 


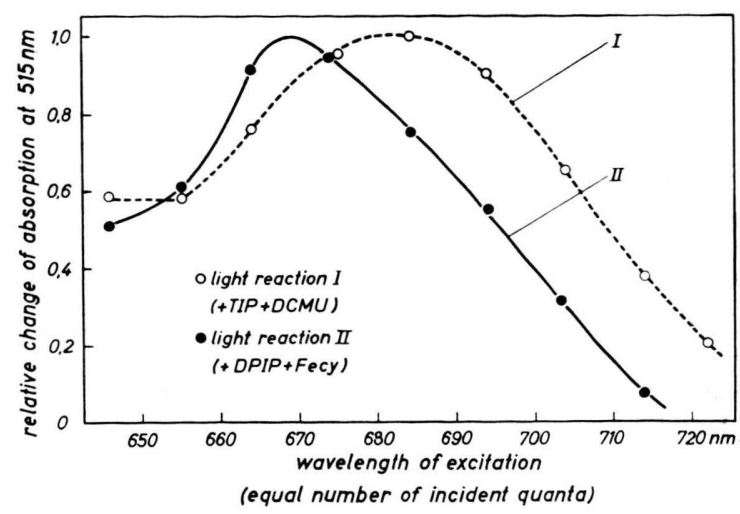

Fig. 5. Normalized action spectra of the absorption change of chlorophyll-b at $515 \mathrm{~nm}$ iflight reaction I (TIP+DCMU) and light reaction II (DPIP + Fecy) respectively are separated. Chlorophyll-concentration $10^{-4} \mathrm{M} / l$, activity of $\mathrm{O}_{2}$-production $6 /(35,8) \mathrm{mM}\left(\mathrm{O}_{2}\right) / \mathrm{M}(\mathrm{Chl}) \cdot \mathrm{s}$, activity of ATP-production 34,6 $\mathrm{mM}(\mathrm{ATP}) / \mathrm{M}(\mathrm{Chl}) \cdot \mathrm{s}$. Tricine-NaOH-buffer: $\mathrm{pH} 4 ; 5 \cdot 10^{-3}$ $\mathrm{M} / l$. Electron acceptor: $\bigcirc$ TIP, resp. $\bullet$ DPIP each $10^{-4} \mathrm{M} / l$. Further additions: $\mathrm{KCl} 10^{-2} \mathrm{M} / l$ Gramicidin $\mathrm{D}$ about $10^{-9}$ $\mathrm{M} / l$. $\bigcirc$ DCMU $5 \cdot 10^{-6} \mathrm{M} / l$. ASC $10^{-2} \mathrm{M} / l$. $\bullet$ Fecy $10^{-3} \mathrm{M} / l$. Reaction volume $1 \mathrm{ml}$. Path length through the cuvette 1,4 mm. Excitation: sharp cut off bandfilters DAL (Schott und Gen.), halfwidth $18 \mathrm{~nm}$, duration $15 \mu$ s, frequency $2 \mathrm{cps}$. Measuring beam: wavelength $515 \mathrm{~nm}$, grating monochromator, optical bandwidth $\Delta \lambda=2 \mathrm{~nm}$, intensity $<400 \mathrm{erg} / \mathrm{cm}^{2} \mathrm{~s}$. $T=22^{\circ} \mathrm{C}$. Electrical bandwidth $\Delta v=4,5 \mathrm{kcps}$. Repetitive flash photometry, 500-1000 flashes were fired.

change at $515 \mathrm{~nm}$ ) with light reaction II in action has been published already by MüLLER et al. in $\mathrm{l}$. c. ${ }^{31}$, that with light reaction $I$ in action by Fork et al. in l.c. ${ }^{32}$. The two action spectra for the field changes in fig. 5 correspond to the well-known action spectra for the electron transfer with light reaction $\mathrm{I}$ in action and light reaction II in action respectively (see e. c. fiig. 14 in l. c. ${ }^{1}$ ).

\section{The Field Strength}

From the result that $t w o$ protons are translocated across the membrane per one turn-over of both light reactions in one electron chain, the value of the difference of the electrical potential $V_{0}$ across the membrane can be calculated by

$$
V_{0}=\frac{2 \cdot e \cdot l}{\varepsilon \cdot \varepsilon_{0} \cdot A} .
$$

The none aqueous insulating layer in the thylakoid membrane, the lipid layer, has a thickness of

31 A. Müller, D. C. Fork, and H. T. Witt, Z. Naturforschg. 18 b, 142 [1963].

32 D. C. Fork, J. Amesz, and J. M. Anderson, Carnegie Institution Year Book 1965-66, p. 473. about $l=30 \AA$ see l.c. ${ }^{33}$. One electron chain covers an area of $A \approx 300 \AA \times 300 \AA^{33}$. The effective dielectric constant of a phospholipid membrane is $\varepsilon \approx 2^{34}$. With these figure it results for the voltage across the thylakoid membrane

$$
V_{0} \approx 50 \mathrm{mV} \text {. }
$$

This corresponds to a field strength of about $1,7 \cdot 10^{5} \mathrm{~V} / \mathrm{cm}$.

Because the absorption change of the chlorophyll-b can increase from short flashes to longer, maximal by a factor 4 see l.c. ${ }^{35}$, and because the relationship between the absorption changes of chl-b is linear, see 1. c. $^{12}$, the maximal voltage across the thylakoid membrane can reach a value up to

$$
V_{\max } \approx 200 \mathrm{mV} \text {. }
$$

From the magnitude of the changes of chl-b in chloroplasts in permanent light ${ }^{37}$ it follows a steady state value of $V \approx 100 \mathrm{mV}$.

\section{Discussion}

It has been shown that each of the two light reactions translocates one proton across the thylakoid membrane if one electron is transferred from $\mathrm{H}_{2} \mathrm{O}$ to a terminal acceptor $\mathrm{A}\left(\mathrm{NADP}^{\oplus}\right)$. Thus, the $\Delta \mathrm{H}^{\oplus} / \Delta \mathrm{e}^{\ominus}$ ratio equals 2 for the elementary act. Moreover, it has been shown that each of the two light reaction sets on one half of the electrical field strength across the thylakoid membrane.

The participation of both light reactions in the electron transfer, in the field onset and in the proton translocation makes it probable that these four processes are directly coupled with each other.

Two possibilities can be discussed for the latter two.

a) Primary the field is set on and than this field causes the proton translocation. $\mathrm{Or}$

b) primary the proton translocation takes place which is automatically accompanied by an onset of the field.

For a discussion the following facts have to be considered. The electrical field is set on in $\leqq 2 \cdot 10^{-8}$ $\sec ^{1,14}$. The proton uptake is probably much slower.

33 W. Kreutz, Z. Naturforschg. 23 b, 520 [1968] ; W. Kreutz u. W. Menke, Z. Naturforschg. 17 b, 675 [1962].

$34 \mathrm{H}$. Davson and J. F. Danielli, The Permeability of Natural Membranes, Cambridge Univ. Press, Cambridge 1952.

35 H. T. Witr, Z. f. Elektrochem. 59, 981 [1955]. 
Fig. 3 reflects a pH-rise time of about $70 \mathrm{msec}$ for stripped chloroplasts. A rise time of $8 \mathrm{msec}$ is indicated if the measurements are carried out on broken chloroplasts isolated in a density gradient. This is shown in fig. 6 . The difference in the response time of the $\mathrm{pH}$ indicator BTB in fig. 3 and fig. 6 may be due to a shielding of BTB molecules from the thylakoid membranes at which the primary proton uptake takes place. It is possible that even this value on broken chloroplasts is not the true one but delayed by unknown effects. So it can be concluded that the proton uptake takes place in $8 \mathrm{msec}$ or faster, but probably much slower than $2 \cdot 10^{-8}$ sec. So possibly first the field is set on and than this field causes the $\mathrm{H}^{\oplus}$-uptake and -translocation. This can in principle be realized by one of the different possibilities discussed by Mitchell in his hypothesis ${ }^{7}$.

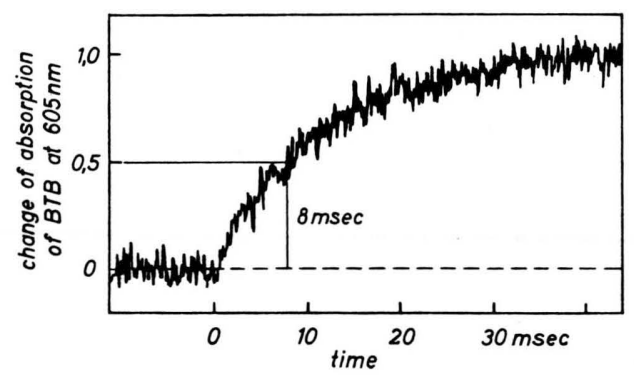

Fig. 6. Time course of the absorption change of BTB at 605 $\mathrm{nm}$ in a suspension of broken chloroplasts which were prepared from a density gradient between glycerol/sucrose $(0,3 \mathrm{~m})=60 / 40$ and glycerol/sucrose $=25 / 75$ in phosphate

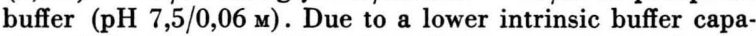
city of these broken chloroplasts light scattering and other intrinsic absorption changes at $605 \mathrm{~nm}$ are negligible in comparison with the BTB signal. Experimental conditions as in fig. 2.

The field may be set on by a rapid transfer of one electron from a donator molecule at the inner side of a membrane to a carrier molecule at the outer side. The reduced carrier molecule may take up a proton from the outer phase, and diffuse as a neutral molecule to the inner side of the membrane. Here it may be reoxidized by an electron acceptor molecule releasing a proton into the inner phase.

According to the results reported above and regarding all the facts which are known on the electron transfer system in photosynthesis - see for instance l.c. ${ }^{1,15}$-, the coupling between the two light reactions, electron transfer, field formation, and proton translocation can be formulated in more detail in the following way (see fig. 7).
Each of the two photoactive chlorophylls $\mathrm{a}_{\mathrm{I}}$ and $a_{\text {II }}$ absorbs in a short flash $\left(\ll 6 \cdot 10^{-4} \mathrm{sec}\right)$ one quantum $h v_{\mathrm{I}}$ and $h v_{\mathrm{II}}$ respct. This absorption is followed by one electron transfer from the chlorophyll to an acceptor. This transfer is assumed to occur at each chlorophyll-a reaction diagonal through the thylakoid membrane from the inner to the outer surface. This can occur in $\leqq 2 \cdot 10^{-8}$ sec. The component of this transfer which is perpendicular to the membrane causes the formation of an electrical potential $V_{0}$. At the end of this process at each light reaction one negative charge $\square$ is located at the outer surface of the membrane and one positive charge $\boxplus$ at the inner surface. In the following the names of the charged molecules known from l. c. ${ }^{1,15}$ are put in brackets.

The negative charge $\square\left(\mathrm{X}^{\ominus}\right)$ of light reaction II reduces plastoquinone $\mathrm{PQ}$ within $\leqq 6 \cdot 10^{-4}$ sec. This is accompanied by an uptake of one $\mathrm{H}^{\oplus}$ from the outer phase.

$$
1 / 2 \mathrm{PQ}+\square \rightarrow 1 / 2 \mathrm{PQH}_{2}+\square-\mathrm{H}_{\text {extern }}^{\oplus} \text {. }
$$

The neutral molecules $1 / 2 \mathrm{PQH}_{2}$ (symbolized in fig. 7 with $\mathrm{PQH}$ ) translocate a hydrogen diagonal from the outer surface of the membrane to the positive charge $\boxplus \mathrm{I}\left(\mathrm{Chl}-\mathrm{a}_{\mathrm{I}}{ }^{\oplus}\right)$ of the light reaction $\mathrm{I}$ at the inner surface which oxidizes (via cytochrome $\mathrm{f}$ ) $1 / 2 \mathrm{PQH}_{2}$. This reaction is accompanied by a release of one $\mathrm{H}^{\oplus}$ into the inner phase. This takes place in $2 \cdot 10^{-2}$ sec.

$$
1 / 2 \mathrm{PQH}_{2}+\square \rightarrow 1 / 2 \mathrm{PO}+\square+\mathrm{H}_{\text {intern }}^{\oplus}
$$

The possitive charge $\boxminus\left(\mathrm{Chl}-\mathrm{a}_{\mathrm{II}}{ }^{\oplus}\right)$ of light reaction II at the inner surface of the membrane oxidizes (via intermediates) $\mathrm{H}_{2} \mathrm{O}$ which is accompanied by a release of one $\mathrm{H}^{\oplus}$ into the inner phase. This takes place in $2 \cdot 10^{-4}$ sec.

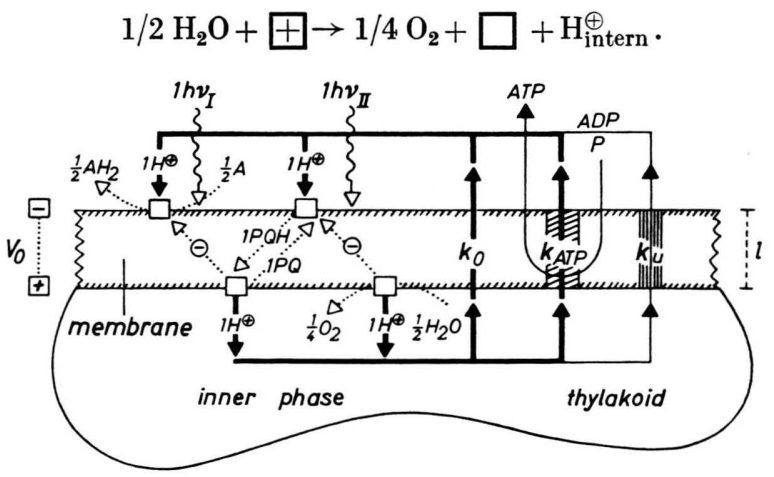

Fig. 7. Correlation between the light reactions, electron transfer, field formation, plastoquinone reaction, and proton translocation in photosynthesis. Details see text. 
The negative charge $\square\left(\mathrm{Chl}_{-} \mathrm{a}_{\mathrm{I}}{ }^{\ominus}\right)$ of light reaction $\mathrm{I}$ at the outer phase of the membrane reduces (via intermediates) the acceptor $\mathrm{A}\left(\mathrm{NADP}^{\odot}\right)$ which is accompanied with a $\mathrm{H}^{\oplus}$ uptake from the outer phase.

$$
1 / 2 \mathrm{~A}+\square \rightarrow 1 / 2 \mathrm{AH}_{2}+\square-\mathrm{H}_{\text {extern }}^{\oplus} .
$$

This can be summarized as follows:

a) An electrical field is set on across the thylakoid membrane in $\leqq 2 \cdot 10^{-8}$ sec.

b) Two protons (without counter-ions) are translocated from the outer into the inner phase of the thylakoid within $\leqq 8 \cdot 10^{-3}$ sec.

c) In toto one electron is transferred from $\mathrm{H}_{2} \mathrm{O}$ to $\mathrm{A}$ $\left(\mathrm{NADP}^{\oplus}\right)$. This ${ }^{4}$ akes place in $2 \cdot 10^{-2}$ sec which is the time of the rate-limiting step which is the oxidation of $1 / 2 \mathrm{PQH}_{2}$.

This concept is in accordance with all the results reported above. A consequence of fig. 7 is - regarding for instance only the events at light reaction II - that with a transfer of one electron - realized in a flash shorter than $\ll 6 \cdot 10^{-4} \mathrm{~s}$ the set on of one half of the electrical field and one $\mathrm{H}^{\oplus}$-translocation should be accompanied with the formation of one half $\mathrm{PQH}_{2}$. This has been shown in

${ }^{36}$ H. H. Stiehl and H. T. W $\mathrm{ItT}$, Z. Naturforschg. 23 b, 220 [1968]. l. c. ${ }^{36,25}$. This $1: 1: 1$ corresponds between the on-set of one half of the field, one $\mathrm{H}^{\oplus}$-translocation and one half $\mathrm{PQH}_{2}$ formation mediated by light reaction II has been proved in a wide range in the following way.

There exists not only $1 \mathrm{PQ}$ molecule between the two light reactions as electron carrier but a pool of about $3-5 \mathrm{PQ}$ molecules with an electron capacity of $6-10^{36,25}$. According to fig. 7 simultaneously with the PQ-pool reduction through $n$ electrons, the uptake of $n \mathrm{H}^{\oplus}$ and a $n$-fold increase of the field (absorption change of e.g. $515 \mathrm{~nm}$ ) should occur. A corresponding strict coincidence of all these three components has indeed been shown up to $n=6$. This is demonstrated in the following paper ${ }^{12}$.

In fig. 7 additionally the results on the proton efflux out of the thylakoid are indicated. The efflux is realized by the intrinsic efflux $k_{0}$, the extra efflux $k_{\mathrm{ATP}}$ during phosphorylation and by the accelerated efflux $k_{\mathrm{U}}$ through an increase of the $\mathrm{H}^{\oplus}$ permeability of the membrane by uncouplers.

A discussion of the whole concept is presented in l. c. ${ }^{15}$.

The authors wish to thank Miss J. Mans for her excellent technical assistance.

${ }^{37}$ H. T. Witt and R. Moran, Z. physik. Chem. 20, 283 [1959]. 